\title{
Gaming across cultures: experimenting with alternate pedagogies
}

\author{
Soma Pillay
Monash University, Churchill, Australia, and \\ Soma Pillay
Monash University, Churchill, Australia, and \\ Reynold James \\ Swinburne University of Technology, Melbourne, Australia
}

\begin{abstract}
Purpose - Higher education is influenced, to an increasing extent, by changing student demographics. This requires educators to design and deliver learning systems which will enhance students' learning experience with innovative, real world and engaging resources. The authors predict that transformations in the learning systems will increase as higher learning institutions seek to add educational value. The authors maintain that current pedagogies in cross-cultural education are insufficiently adapted to student learning-style needs. This problem is particularly noticeable in one cross-cultural setting. This study aims to explore games, as an alternate pedagogy, to enhance learning systems.

Design/methodology/approach - Students' feedback formed the primary qualitative data for this study. The paper develops a conceptual model which provides an organised framework to manage intercultural differences, using games. The Mapping, Bridging, Integrating (MBI) model creates an opportunity for students to appreciate differences and understand the model's implications for their careers in international management.

Findings - Participants' responses to the games were overwhelmingly positive. Participants' responses indicated games as a preferred method for developing the intercultural competence, team work, decision making and self awareness skills essential for business and entrepreneurship.

Practical implications - There is a growing need to consider and align the relationship between education, the increasing cultural diversity in student populations, and the learning and teaching styles of a changing student population in order to enhance the extent of expected knowledge transfer. Originality/value - In this study, the authors adopted a qualitative approach to trialling the use of games in a cross-cultural context with the view to reducing international cross-cultural barriers and developing skills in intercultural competence, self awareness, collaborative working and decision making. This study shows the need for alternative, more integrative models of education comprising elements of complexity that fit with an increasingly complex world.
\end{abstract}

Keywords Games, Intercultural competence, International, Australia, Higher education, Learning Paper type Research paper

\section{Introduction}

Intercultural competence is widely described as a key competence of the twenty-first century. Possessing this attribute is critical to the success of today's international manager. Acquiring intercultural competence, that is the capacity to change one's knowledge, attitudes and behaviour to be open and flexible to other cultures, is critical for individuals' survival in our modern globalised society. Integral to the success of organisations engaged globally is their employees' ability to connect with others across cultures, equipped with their "dynamic, ongoing, interactive and self-reflective" competencies (Freeman, 1995). Two other competencies, alongside intercultural competence, are consistently identified by business leaders as factors critical to success in industry, namely, teamwork and problem solving (Goltz et al., 2008). Both of these

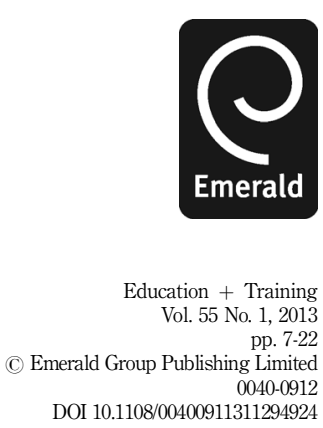

Received 7 October 2011

Revised 23 January 2012

7 March 2012

Accepted 3 May 2012 
ET

55,1

competencies, one could reason, are inseparable from the aspect of intercultural competence in the context of globally engaged organisations. Yet another felt need within the area of entrepreneurial education which is currently lacking is the role that emotions linked to failure play (Shepherd, 2004), given that most entrepreneurs encounter failure before success. Linking these (four) facets, one may argue that a highly effective means to learn or teach these competencies is through experiential methods, that is "learning by doing", and through the use of games (Lope and Baghero, 2010; Verzat et al., 2009). In this study, we adopted a qualitative approach to trialling the use of games, as an alternate pedagogical method, in a cross-cultural context with the view to reducing international cross-cultural barriers and developing competencies in intercultural competence, self-awareness, collaborative working and decision making. The trials took place within one postgraduate class of a large Australian university. The classes comprised a heterogeneous mix of local and international students. Our choice of research direction was influenced by the strong body of literature supporting the use of games for developing the competencies discussed, and on the extent of lack of intercultural integration between local and international students within Australian universities (Leask, 2009). Throughout this paper, we detail the findings on our use of two games, Pasta Game 1 and Pasta Game 2 (see Appendix).

\section{Theoretical background}

Globalisation has resulted in organisations' growing demand for interculturally sensitised employees with enhanced team working and problem-solving abilities (Goltz et al., 2008). Some scholars suggest that the way to creating such employees is through universities training them before they enter the workforce (Freeman, 1995). The advantages of this approach are explained by Azriel et al. (2005) and Leask (2009) who claim that greater demand for education has resulted in classrooms increasingly comprising students from diverse ethnic, socio-economic and diverse age groups, owing to larger numbers of mature age students being drawn to study consistent with the current life-long learning trend. With technology and globalisation reducing the size of the business environment and increasing the diversity amongst the workforce, the need for business students to acquire intercultural skills has increased. Yet another reason for universities to be ideal training grounds for imparting intercultural competence and allied skills is campus diversity; a valuable resource for developing teachers' and students' intercultural perspectives in a low-risk environment (Leask, 2009).

\section{Traditional pedagogies}

While the foregoing suggests a clear case for an increased demand for the skills discussed being met through higher educational institutions the reality is, however, that universities and educational institutions are often failing to deliver such outcomes. A key reason for this lack is in the less than effective "traditional only" pedagogical styles used by educational institutions in teaching and learning sensitive aspects such as intercultural competence and teamwork, and entrepreneurship-related competencies such as the ability to cope with emotions arising out of failure (Shepherd, 2004). Some scholars maintain (Corno and Snow, 1986; Sternberger, 1995; Becker and Watts, 1995) that educators are being increasingly critical of the lack of relevance of traditional pedagogical roles of "professor as lecturer and student as note taker", which fail to consider the individual differences and learning styles in diverse student populations. According to Axley and McMahan (2006), "the traditional mechanistic approach to 
management and management education is limited". They stress the need for alternative, more integrative models of education, comprising elements of complexity that have a fit with an increasingly complex world. Selvarajah (2006) discusses the linkages between education systems and culture and states that students from varying cultures respond to educational styles differently and that the traditional models do not accommodate these aspects.

We maintain that the existing models of developing intercultural competence are inadequate in Australian business higher education. Lope and Baghero (2010) describe deficiencies in the pedagogical systems used across the world in entrepreneurship education despite learning being considered central to the entrepreneurial development process. Conspicuous in its absence, seems to be the established fact that "In education, what is taught is inextricably linked to how it is taught" (Dewey, 1916). This view is supported by Selvarajah's (2006) research which explores the need to consider and align the relationship between education, the increasing cultural diversity in student populations, and the learning and teaching styles of a changing student population in order to enhance the extent of knowledge transfer. He argues that postgraduate students in management studies from different cultural backgrounds, ethnicities and nationalities may respond to educational styles differently, and that forcing students into traditional molds does not augur well in a globalising world. Hence, we maintain that understanding the importance of diverse learning styles from an experiential perspective is crucial as our general life experiences and societal demands influence our ability to manage conflict between being concrete or abstract and between being active or reflective (Kolb and Kolb, 2005; Ng et al., 2009). Such thinking is broadly supported by Ruben (1999), Philpot and Peterson (1998) and Verzat et al. (2009), who maintain that adoption of alternative pedagogies, to enhance teaching and learning effectiveness to diverse student groups within business education, is the answer to deficiencies in the traditional methods. Interestingly, while the availability of resources was earlier considered a barrier to the inclusion of simulation and gaming for teaching and learning in higher education, the same was displaced by another "more serious" perceived barrier, namely, the suitability of, and risk attached to, learning methods such as games (Lean et al., 2006). However, such fears seem to be unfounded and the benefits exceed the costs involved in the case for the use of games as an alternative experiential pedagogical device to traditional methods. For the purposes of our study, we adopt the definition of "games" used by Verzat et al. (2009), that is, "an educational device with discrete objectives [...] with respect to the participants' learning, used in the context of known boundaries".

Intercultural competence through experiential learning. Experiential learning is a process whereby concepts are "formed and modified by experience" (Kolb, 1984). Institutions, over the years, have attempted to introduce experiential learning methodologies to achieve learning objectives within their courses. Achieving such learning objectives through experiential methodologies equip students with abilities, knowledge and greater awareness of certain real-world phenomena (Kolb and Kolb, 2005; Kayes, 2002; Kolb, 1984; Yamazaki and Kayes, 2004). In this case, experiential learning was a key to developing intercultural competence, such as greater awareness of cross-cultural differences; understanding behaviour when working with people from different cultures; and developing appropriate business knowledge. The growing emphasis on experiential approaches may be attributed to the ever increasing mobility of people across borders ( $\mathrm{Ng}$ et al., 2009). Despite the important role that global assignments play in international management, there appears to be a dearth of

Gaming across cultures 
ET

55,1

10

knowledge around the importance of experiential learning methodologies, such as games used in pedagogies, to develop intercultural competence and the preparation of future international managers.

The case for using games as a pedagogical device

Simulation-based learning, which encompasses games, is an established alternative pedagogy to traditional teaching methods and includes three types of activity, first, role plays; second, gaming; and third, computer simulations. The commonality underscoring these three activities is their ability to allow students to have an imaginary world within which to act out given situations (Moizer et al., 2009). The importance and effectiveness of the use of games as a pedagogical technique in professional education is well supported by the literature, as is the case for adapting teaching methods to what is being taught (Verzat et al., 2009; Azriel et al., 2005). Cohen and Rhenman (1961) trace the roots of management (business) games to military organisations, which have been using these for centuries, and state that the American Management Association first introduced games to the civilian world in 1956. They describe two main reasons for using games in business teaching as playing games being a lot of fun, involving a high degree of personal involvement, and with a competitive spirit that is engendered, and important aspects of an education programme are taught much more effectively through management games than in any other way. Schreiber (1958), as early as in 1958, described the role and benefits of games as attractive and being able to supplement traditional teaching techniques with unorthodox means. More recently, Brozik and Zapalska (2000), who view gaming as a valid educational experience, lend support to such thinking. Others maintain that interactive teaching methods, including simulations and games, offset the limitations of traditional methods, increase active learning, promote creativity and are of excellent value in training for interpersonal skills (Pedersen and Hofstede, 1999; Philpot and Peterson, 1998; Ruben, 1999).

Entrepreneurship-related studies have received a boost in the past decade, due to organisations seeking to become more entrepreneurial, by promoting intrapreneurship for example. Research into the pedagogical aspects relating to entrepreneurship education reveals that entrepreneurship students who had been taught courses through the "learning by doing" (simulation and gaming) pedagogy scored higher in achievement behaviour, achievement and self-esteem cognition and innovation cognition, compared to their counterparts (Lope and Baghero, 2010) who learnt through traditional pedagogies. In addition, since games allow participants to experience the emotions associated with failure (given that most entrepreneurs fail before they succeed), well-planned games within classrooms serve as an ideal learning ground for students to experience, and learn from, failure, in a relatively safe environment (Shepherd, 2004). It is worth mentioning at this point that games, and the advantages that accrue from their use, are highly analogous to action learning - yet another alternate pedagogical method. Action learning is described by Raelin (2006) as a technique that facilitates learners to engage together in real time work problems and allows the knowledge gained in one context to be used in real life situations by practitioners. The resulting positive benefits closely correspond with the benefits derived from gaming in business education.

While the advantages of, and situations in which, simulations are a substitute for traditional methods are manifold, their true value is still underestimated in the education field (Zantow et al., 2005). Not least, while the time taken to complete games 
and to arrive at decisions vary vastly between games, the advantages in selecting games that can be completed within a single class period include the flexibility of their application, the diversity of ideas through a single game, and the potential of combining real educational experience for students without being over complicated or overpowering (Brozik and Zapalska, 2000). However, this presents many challenges in a highly cross-cultural setting. Understanding the lenses through which people view the world is anything but easy. This problem is exacerbated when students prepare assessments in a cross-cultural team. improve intercultural competence. We develop the following research question:

We develop a conceptual model which provides an organised framework to manage intercultural differences using games. The mapping, bridging, integrating (MBI) model (adapted from Lane et al., 2000) creates an opportunity for students to appreciate differences and understand their implications for their careers in international management.

Conceptual model for managing intercultural competence using games: an MBI perspective

We maintain that there are three sets of skills integral to intercultural competence which games, as a pedagogical device, may assist in achieving: mapping, bridging and integrating as illustrated in Figure 1.

The MBI model, adapted from Lane et al., 2000, is based on three skills: mapping which allows for the understanding of cultural differences amongst team members; bridging which allows for effective cross-cultural communication amongst members; and integrating which allows for different perspectives to be brought together and to be built upon.

Mapping. Our intention was to use alternate pedagogies, such as games, to manage intercultural competencies. Students were encouraged to develop a "cultural map" based on their team members' characteristics and their cultural background, in terms of observable patterns. We argue that a good cultural map allows international managers to obtain accurate information about cross-cultural management issues and concerns (Lane et al., 2000). For the purposes of this paper, we describe a cultural map

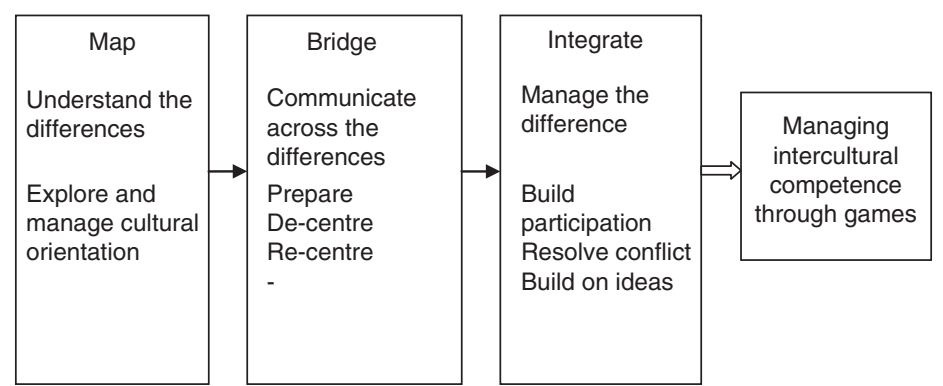

In this study, we investigate the use of games as alternate pedagogical devices to

$R Q 1$. Are games an appropriate pedagogical device to meet the specific learning needs of highly cross-cultural teams?

\section{Gaming across} cultures 
ET

55,1

as facilitating one's ability to describe oneself and others to allow predictions and explanation of team-based behaviour with the intention of managing a high-performance team. Students who become international managers without having experienced cross-cultural challenges tend to develop their own cultural mapping unconsciously. Having a formal framework on which to assess their observations helps to accelerate the learning process.

Bridging. After students observe patterns in values and cultural orientations, they attempt to understand these patterns from their own perspectives as well as the perspectives of others. It is this level of mapping skill that students develop which provides a platform or foundation for effective bridging.

Prepare: like the workforce, the more culturally diverse a classroom is, the more challenging it becomes to manage intercultural competence. Two predictors are crucial for "preparedness": motivation and confidence. Students are motivated, through interactive non-traditional methods, to communicate across a cultural boundary, to be both understood and to understand their team members. Motivational theories come into play as students are challenged to be the winning team. Students who are normally confident may find that they are less confident in a cross-cultural setting. Confidence is the belief that it is possible, through teamwork, to overcome any communication or cultural barriers.

De-centre: de-centring is a process of moving away from your own position, or centre, and moving into the mind of the other person. In this process messages are sent in a way that will allow students to understand others and to allow others to understand them. Lane et al. (2000) maintain that this requires an important skill, empathy: feeling and understanding as the next person does. In international management, many international assignments fail due to managers not possessing cross-cultural competencies such as having the ability to empathise (Deresky and Christopher, 2008; Phatak et al., 2005; Scullion and Linehan, 2005). Good de-centring requires good mapping skills, in that the map warns you of surprises and problems.

Re-centre: this stage requires students to establish a common reality and to agree on forming mutually agreed upon rules. A cross-cultural team that struggles with this requirement may find that some team members are frustrated at the outset due to incompatibilities. Again skills in mapping will dictate how to find a common reality and will give teams a point of leverage.

Integrating. Integration allows students to manage differences through effective participation, conflict management and building on ideas. This process addresses cultural challenges when working in a cross-cultural setting.

Participation: depending on the cultural background of students, they may or may not choose to verbalise their opinions freely. For example, people who have lived in a high powered and hierarchical society may feel less inclined to express their ideas to a higher status person or to the group leader. In this stage team members actively facilitate participation.

Conflict management: the more multicultural a team is the greater the likelihood of a wide range of opinions, which may present cross-cultural challenges. Through effective mapping and bridging, such conflict should, ideally, result in creativity of thoughts and ideas.

Building on ideas: with a well-understood mapping framework, good communication skills, active participation and good conflict management techniques the team is able to progress and build on ideas. 
Research methodology

The research context

The pasta game was part of a teamwork programme in a master of commerce programme at an Australian University. The students enroled in this unit come from multicultural backgrounds, an aspect which has presented challenges with team-based assessments in the past. One of the subject's learning objectives is "to develop cross-cultural competencies and a "global mindset" which will be demonstrated through experiential learning". This project was aimed at preparing future international managers to foster teamwork skills and innovation capabilities in order to succeed in the real world; addressing a recurring challenge that facilitators faced with group dynamics in cross-cultural teams (e.g. social loafing, conflict management, cultural incompetence and general communication); and as group-based assessments often resulted in poor grades, the introduction of games was an initiative to address these problems and to create interactive opportunities to make learning in a cross-cultural setting effective.

\section{The pasta game}

Students were required to work in pre-assigned, cross-cultural teams in two games using pasta in which they were required to construct an arched bridge and a tower using pasta, amongst other materials. Our primary objective in using games was to encourage students to participate in the learning process, encourage teamwork (Marks et al., 2001) in a highly cross-cultural setting, and, by doing so, allow students to prepare for the real world. We also sought to further the understanding of the role that games play in the educational process. For the purposes of this research, minor adaptations were made to Kofoed and Rosenorm's (2003) spaghetti game. Students were allowed a 15-minute debriefing session which assisted in the mapping process. After completion of the first game, students were allowed 20 minutes to debrief on their teams experiences. Several open-ended questions were asked to guide the debriefing session. At the end of the game, students had the opportunity to reflect as a group on their experiences. This information formed part of their responses and was used as primary data for this project. According to Lyles et al. (1992), introducing a gap between the games evokes a difference in attitudes and team abilities.

\section{Participants}

Participants were either full time or part time students enroled in a masters (commerce) programme at an Australian university. The student demographics indicate a diverse and highly multicultural cohort of students (see Table I). In total, 81 students participated in the study. Students were pre-assigned to groups with no more than two students from the same country in each group.

We analysed our findings using a qualitative approach coupled with the theory from the more established fields of cross-cultural management and educational science.

\section{Data collection and analysis}

We collected data from 81 students enroled in a masters' degree. The group debriefing sessions formed part of the primary data collected by attending teaching staff. Demographical information was collected through a structured questionnaire. Students were asked open-ended questions about the group's experiences. Student reactions to the game experience were categorised and themed under "mapping", "bridging" and "integrating" and were reviewed for recurrent or common themes.
Gaming across cultures 


\section{ET}

55,1

14

(3) Country of birth
(2) Age (categories)
(1) Work experience
Table I.

Demographics of participants

A common theme running through the interviews was the respondents' references to teamwork and the fun way to adopt cross-cultural skills for the "real world". The participants' descriptions and interpretations of teamwork displayed many dimensions and confirmed that they had definitely learned about alternate pedagogies such as games in developing certain skills.

\section{Results}

In line with the mapping phase of Lane's model (2000), we sought to examine students' reactions to the pedagogical experience as a first step to querying its effectiveness as a pedagogical device. Below, we present student perceptions of the pasta game. Results indicate that students were extremely positive about their experiences.

Generally, students perceived the experience as a positive learning one:

The group members were very motivated. The ideas kept flowing throughout the tasks. Even though we didn't complete the first task, everyone was motivated enough to complete the second one. "Arguments were ironed out through group discussions. I was pretty happy with the way my group preformed."

Working in cross-cultural and, at times, unfamiliar settings presented certain challenges which were quickly resolved during the bridging stage:

My being part of this allowed me to identify readily with the storming phase of Tuckman's model where group members are seen to propel in different directions and away from each other due to uncertainty.

Students commented on the pedagogical benefits of innovative methodologies such as games as opposed to traditional highly theoretical styles:

Games like these are a good way to learn and instead of reading the theory, it teaches the practical part, which in my view is very important. Everyone was motivated to the tasks and came up with great ideas. Gaming method helped a lot more in learning and was more creative than the normal method.

Participants often linked the learning experience to the learning objectives:

Games are an excellent way to inspire and motivate in a team environment, however, it does truly need a good facilitator to run this type of learning methodology. My reason for this is that not all personality types or learning types are open to this type of learning. Therefore it is up to a good facilitator to adapt his or her learning activity to ensure the learner is feeling 
included. Personally, I was able to observe my own behaviour in a different light and feel I want to work on this some more.

In that light, I am confident this type of learning would also highlight negative team reactions and again, having a good facilitator would see that this type of interaction would be monitored and managed well so optimum learning was achieved.

Participants became deeply engaged in the experience and began to think critically about their experiences. Such experiential learning (reflective observation, debriefing) are crucial to the process of transferring knowledge gained from experiential learning activities back to the workplace (Meyer, 2003). Although all experiential learning offers the opportunity for learning through active discovery rather than passive learning, games, as a form of experiential learning, have certain advantages that further accentuates the benefits of "learning by doing", such as developing cultural awareness. Participants' responses highlighted that games exposed them to phenomena which in turned allowed them to understand and appreciate underlying cross-cultural theories.

Various discoveries were made through the mapping stage:

The creativity that was needed for this task, allowed me to see team members in a different light which I felt sped up the "getting to know you" process. Another interesting aspect of the experience is that I have learnt that breaking up people who congregate in peer groups and natural group formations (due to similar background, nationality or age etc.) can really help larger groups understand people quickly and also provides the opportunity for some "takeaway" learning. It really does assist in smashing (or eliminating) the ideal where some people believe they cannot learn from others who are not similar to them. It is so important to break through these barriers.

Students made positive remarks when asked to reflect on the strengths of the exercise:

I certainly feel more comfortable with my group team members now and this would help with our future interactions.

I think games are always fun, and they generally bring out the different personalities of the individuals provided that they are also actively participating. For example, one of the members of the group was very determined. I knew he would be a dedicated student but I probably wouldn't have seen this side of him until we played the games today.

Participants commented on the gender aspect of teamwork which encompassed part of the mapping and bridging phase of our conceptual model:

I personally discovered through this exercise, that males in comparison to females work in a different way. The females in the group laughed and joked and the male was very serious and persistent - perhaps also due to cultural differences.

In the early stages of the group formation there was some discussion around identifying each team members strengths i.e. creativity, thinking outside the box, but the group consensus was to work cooperatively and to draw on each person's ability as the activity progressed. The group did not allocate tasks around specific areas, but rather chose to build on each person's thinking.

As this unit had a strong theoretical component to it, students were able to link theories on group formation to their learning experience:

Diversity, in terms of culture and different ways of approaching the activities presented in the form of the thinking process to achieve the goal. That is, one member of the group focused on giving consideration to "how" the task would meet the end goal while another focused more on "doing" the task without fully explaining an end vision. These characteristics linked directly
Gaming across cultures 
ET

55,1

\section{6}

to cultural backgrounds and added interesting group dynamics. The team worked quickly through the forming, storming and norming stage but never really achieved a performing stage. There was respect within the group and consideration for each person's point of view.

This exercise encouraged reflective thinking which assisted participants to work through the experience:

The key learning point for the future is developing a greater understanding of cultural differences in terms of thinking and approaches to problems. Some people want to act whilst others are thinkers.

Diversity' (2 male, 1 female / 2 Australians 1 Pakistani) was considered implicitly. The focus on being egalitarian and inclusive was noticed and the absence of clearly defined roles frustrated and restricted progress. "I believe that the use of games methodology is powerful in encouraging self reflection. There is no doubt that the pre-priming of content (studying group dynamics the week before, reading Belbins Team Roles prior) would enhance the application of theoretical integration to the experience. The game, no matter how trivial, is a way of focusing the students to task. Task focus allows the behaviours to be real and not contrived, which gives students an excellent insight into themselves and the behaviours of others.

Responses above indicate that teamwork is significant in international management as much of the work in international assignments is dependent upon effective teamwork. Participants also emphasised the interpersonal processes at play within their diverse teams. These included awareness with respect to conflict management, team motivation, confidence building and communication across cultures. Participants indicated that in a cross-cultural context, intercultural competence is achieved cooperatively rather than individually and that teamwork skills often supersede technical skills. However, in the context of intercultural competence and international management education, participants believed that effective teamwork skills are developed through experiential learning opportunities.

\section{Discussion}

In this study we adopted a qualitative approach to trialling the use of games in a crosscultural context, as an alternate pedagogical method, with the view to reducing international cross-cultural barriers and developing competencies in intercultural competence, self-awareness, collaborative working and decision making. The results generally indicate that students felt positive about using games and interactive simulations as learning devices.

From the data, we highlighted selected quotes which contributed to form our conceptual model (Table II).

Several scholars (e.g. Azriel et al., 2005; Leask, 2009) claim that the competencies discussed are best taught and learned at universities and educational institutions, given the growing diversity existing within these. The potential advantage this approach holds is educating employees in the competencies discussed before they enter the workforce. However, a major impediment to this approach is the use of traditional, rather than innovative, pedagogical methods to teach these competencies at universities, regardless of students' cultures or learning styles (Selvarajah, 2006). This is supported by one participant's response:

This andragogy style of learning was most appropriate for students studying this unit. It provided a practical environment in which to utilise skills in dealing with cultural differences and to highlight areas for future development. The action learning/experiential approach enabled each team member to identify their strengths and reflect. 


Mapping
My being part of this allowed
me to identify readily with the
storming phase of Tuckman's
model where group members
are seen to propel in different
directions and away from each
other due to uncertainty

One member of the group focused on giving consideration to "how" the task would meet the end goal, whilst another focused more on "doing" the task without fully explaining an end vision. These characteristics linked directly to cultural backgrounds and added interesting group dynamics. The team worked quickly through the forming, storming and norming stage but never really achieved a performing stage. There was respect within the group and consideration of each person's point of view I personally discovered through this exercise that males in comparison to females work in a different way. The females in the group laughed and joked and the male was very serious and persistent - perhaps also due to cultural differences'

\section{Bridging}

Integrating

The group did not allocate tasks around specific areas, but rather chose to build on each person's thinking

'The creativity that was needed for this task allowed me to see team members in a different light which I felt sped up the "getting to know you" process'

I felt the group quickly set to task and were motivated by this in itself, which served for typical group interaction to flourish'
The game, no matter how trivial, is a way of focusing the students to task. Task focus allows the behaviours to be real and not contrived, which gives students an excellent insight into themselves and the behaviours of others 'Nervous, full of energy, enthusiasm - task orientated wanting to complete task successfully. There was no conflict, we had lots of socialising and discussion and everyone's ideas were taken onboard'
'There was planning and testing what we were doing and altering our goals when things did not work. No one was blamed, it was done in a good friendly manner'
Table II. MBI Protocol and emerging themes

There are significant advantages, as reflected in participants' responses, in adopting an experiential learning approach, in this case, through the use of games. Participants enjoyed the experience of learning through games; however, a particular strength of the use of games, according to participants, is that games encourage receptivity to knowledge transfer because they engage multiple learning dimensions in a crosscultural setting. The debriefing session was crucial in that participants reflected on the cognitive, emotional and behavioural elements consistent with experiential learning. Kolb's model of experiential learning highlights that concrete experiences can stimulate learners to reflect on their experiences. In this study, participants were given the opportunity to debrief and their reflection led to refining, and the formation of new, course concepts. Participants tried out new concepts by actively experimenting with them, for example, effective communication skills and effective leadership skills in a cross-cultural setting. Therefore, experiential learning in a cross-cultural setting is crucial to the process of transferring knowledge gained from such experiential activities back to the workplace (Hoover et al., 2010). 
ET

55,1
The literature listing the advantages of employing games (in lieu of, or to supplement, traditional teaching methods) is rich and provides a range of varied reasons for adopting them as a preferred method for teaching students the intercultural, team working, decision making and self-awareness skills that are essential for business and entrepreneurship. Azriel et al. (2005) used Maslow's hierarchy of needs to argue that games are a means of increasing motivation levels of international and non-traditional students. This was reflected in one student's comments:

I believe this was a motivational way to learn. While the unit itself is focused on an instructional style of learning, this methodology provided an opportunity for students to use existing knowledge and skill and to build on that in a practical manner. It also enabled students to learn in a more creative environment and, as such, address different learning styles.

Game playing addresses students' lower level (i.e. safety) needs and may lead to a reduction in stress as they are not required to respond individually in a classroom setting. Pedersen and Hofstede (1999) describe the capacity of games to impart lessons in interpersonal effectiveness. Other scholars argue that games and non formal curricula present rich opportunities for participants of different cultures to interact closely with each other and to overcome misunderstandings arising out of cultural differences between local and international students (Greenblat, 1989, cited in Pedersen and Hofstede, 1999; Leask, 2009). This last aspect is especially significant to universities in Australia and serves as an impetus for this study, that there has been a significant increase in the overseas student population and there is an apparent lack of engagement between the local and international student communities (Leask, 2009). Warner (2005) describes games as being useful to help students connect theory to real-world settings and cites the arguments of like-minded authors (Brozik and Zapalska, 2000; Shaw and Fairhurst, 2008) who claim that, besides reinforcing concepts covered in class, games provide the benefit of being a fun factor and assist in breaking routine.

\section{Limitations}

While our findings highlight the opportunities that games present as a pedagogical tool, our research is not without its shortcomings and limitations. Some groups reported negative emotions while playing the game, yet other groups' members noted their lack of understanding of the link between the learning device and the subject matter. Such reactions were not dominant, however, and failed to resurface in the responses of other participants. We chose, therefore, not to explore further this negative perception of games. During the interviews, we collected rich qualitative data that illustrate students' awareness of team processes, however, the information collected does have its limits. Whether student learning translated into improvements in the real world is an important consideration. As teamwork within cross-cultural settings is a complex area of study, we suggest that additional qualitative work, that is observing teamwork in action before and after such interventions, could provide enriched insight (Verzat et al., 2009). Adding a quantitative dimension to a subsequent study could more precisely probe causal relations between students' learning and their experience of the game. Therefore, a longitudinal dimension to such a study which adds to its validity is suggested. 


\section{Conclusion}

Having addressed the main research question, our findings indicate that using games is effective in enhancing learning in a highly cross-cultural setting. The use of games, through mapping, bridging and integrating, enables collaboration and peer learning (Lane et al., 2000; Verzat et al., 2009; Hindle 2002; Loyd et al., 2005; Squire and Jenkins, 2003; Shaw et al., 1999; Schreiber, 1958) and challenges students' skills and beliefs (Zantow et al., 2005). We maintain that games are an innovative pedagogical device for today's generation, given the multicultural and diverse landscape of educational institutions and, more particularly, to management students who respond poorly to passive pedagogies (Felder and Silverman, 1988). In this instance, we used the pasta game to enhance students' teamwork experience. We found student reactions overwhelmingly positive and attribute this to the game's active and novel nature. We maintain that games entice students into a period of reflective "play". While Dewey (1916) believed in the often "accidental" output of educational growth through play, we developed a conceptual framework which guided the thought processes of students to manage themselves in a cross-cultural setting.

\section{References}

Axley, S.R. and McMahan, T.R. (2006), "Complexity: a frontier for management education", Journal of Management Education, Vol. 30 No. 2, pp. 295-300.

Azriel, J., Erthal, M. and Starr, E. (2005), "Answers, questions and deceptions: what is the role of games in business education?”, Journal of Education for Business, Vol. 81 No. 1, pp. 9-13.

Becker, W. and Watts, M. (1995), "Teaching methods in undergraduate economics", Economic Enquiry, Vol. 33 No. 3, pp. 692-700.

Brozik, D. and Zapalska, A. (2000), "The restaurant game", Simulation Gaming, Vol. 31 No. 3, pp. 407-10.

Cohen, K. and Rhenman, E. (1961), "The role of management games in education and research", Management Science, Vol. 7 No. 2, pp. 131-66.

Corno, L. and Snow, R. (1986), "Adapting teaching to individual differences among learners", in Wittrock, M.C. (Ed.), Handbook of Research on Teaching, 3rd ed., McMillan, New York, NY, pp. 605-29.

Deresky, H. and Christopher, E. (2008), International Management: Managing Across Borders and Cultures, 5th ed., International Ed, Pearson Prentice Hall, New York, NY.

Dewey, J. (1916), Democracy and Education, The Free Press, New York, NY.

Felder, R.M. and Silverman, L.K. (1988), "Learning and teaching styles", Engineering Education, Vol. 78 No. 7 , pp. $674-81$.

Freeman, M. (1995), "Peer assessment by groups of group work", Assessment and Evaluation in Higher Education, Vol. 20 No. 3, pp. 289-301.

Goltz, S.M., Hiatapelto, A.B., Reinsch, R.W. and Tyrell, S.K. (2008), "Teaching teamwork and problem solving concurrently", Journal of Management Education, Vol. 32 No. 5, pp. 541-62.

Hindle, K. (2002), "A grounded theory for teaching entrepreneurship using simulation games", Simulation and Gaming, Vol. 33 No. 2, pp. 236-41.

Hoover, J.D., Giambatista, R.C., Sorenson, R.L. and Bommer, W.H. (2010), "Assessing the effectiveness of whole person learning pedagogy in skill acquisition", Academy of Management Learning \& Education, Vol. 9 No. 2, pp. 192-203.

Kayes, C.D. (2002), "Experiential learning and its critics: preserving the role of experience in management learning and education", Academy of Management Learning \& Education, Vol. 1 No. 2, pp. 137-49.
Gaming across cultures

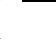


ET

55,1
Kolb, D.A. (1984), Experiential Learning: Experience as the source of Learning and Development, Prentice Hall, Englewood Cliffs, NJ.

Kolb, A.Y. and Kolb, D.A. (2005), "Learning styles and learning spaces: enhancing experiential learning in higher education", Academy of Management Learning and Education, Vol. 4 No. 2, pp. 193-212.

Kofoed, L.B. and Rosenorm, T. (2003), "A game in the game", in Riis, J.O., Smeds, R. and Nichoson, A. (Eds), Environmental Interactive Learning in Industrial Management, Proceedings of the 7th International Workshop on Experimental Learning in Industrial Management, May, Center for Industrial Production, Aalborg University, Aalborg.

Lane, H.W., DiStefano, J.J. and Maznevski, M.L. (2000), International Management Behaviour, Text, Readings and Cases, Blackwell, West Sussex.

Lean, J., Moizer, J., Towler, M. and Abbey, C. (2006), "Simulations and games: use and barriers", Higher education, Vol. 7 No. 3, pp. 227-42.

Leask, B. (2009), "Using formal and informal curricula to improve interactions between home and international students", Journal of Studies in International Education, Vol. 13 No. 2, pp. 205-21.

Loyd, L., Kern, D. and Thompson, L. (2005), "Classroom research: bridging the ivory divide", Academy of Management Learning and Education, Vol. 4 No. 1, pp. 8-21.

Lope, P.Z. and Baghero, Z.A. (2010), "Improving university students' entrepreneurial attitude through learning by doing method", The Journal of International Social Research, Vol. 3 No. 14, pp. 298-306.

Lyles, M., Near, J. and Enz, C. (1992), "A simulation for teaching skills relating to organisational self-renewal”, The Journal of Management Development, Vol. 11 No. 7, pp. 39-58.

Marks, M., Mathieu, J. and Zaccaro, S. (2001), "A temporally based framework and taxonomy of team processes”, Academy of Management Review, Vol. 26 No. 3, pp. 356-76.

Meyer, J.P. (2003), "Four territories of experience: a developmental action inquiry approach to outdoor adventure experiential learning”, Academy of Management Learning and Education, Vol. 2 No. 4, pp. 352-63.

Moizer, J., Lean, J., Towler, M. and Abbey, M. (2009), "Simulations and games: overcoming the barriers to their use in higher education", Active Learning in Higher Education, Vol. 10 No. 3, pp. 207-10.

Ng, K.Y., Dyne, L.V. and Ang, S. (2009), "From experience to experiential learning: cultural intelligence as a learning capability for global leader development", Academy of Management Learning and Education, Vol. 8 No. 4, pp. 511-26.

Pedersen, P. and Hofstede, J. (1999), "Synthetic cultures: intercultural learning through simulation games", Simulation Gaming, Vol. 30 No. 4, pp. 415-20.

Phatak, A.V., Bhagat, R.S. and Kashlak, R.J. (2005), International Management, Managing in a Diverse and Dynamic Global Environment, MacGraw Hill, New York, NY.

Philpot, J. and Peterson, C.A. (1998), "Improving the investments or capital markets course with stock market specialist", Financial Practice and Education, Vol. 8, pp. 118-24.

Raelin, J. (2006), "Does action learning promote collaborative leadership?", Academy of Management Learning and Education, Vol. 5 No. 2, pp. 152-68.

Ruben, B.D. (1999), "Simulation, games and experience based learning: the quest for a new paradigm for teaching and learning", Simulation and Gaming, Vol. 30 No. 4, pp. 8-12.

Schreiber, A. (1958), "The theory and application of the management game approach to teaching business policy", The Journal of the Academy of Management, Vol. 1 No. 2, pp. 51-7.

Scullion, H. and Linehan, M. (2005), International Human Resource Management, Palgrave Macmillan, New York, NY. 
Selvarajah, C. (2006), "Cross cultural study of Asian and European student perception: the need to understand the changing educational environment in New Zealand", Cross Cultural Management: An International Journal, Vol. 13 No. 2, pp. 142-55.

Shaw, J., Fisher, C. and Southey, G. (1999), "Evaluating organizational behaviour teaching innovations: more rigorous designs, more relevant criteria and an example", Journal of Management Education, Vol. 23 No. 5, pp. 509-36.

Shaw, S. and Fairhurst, D. (2008), "Engaging a new generation of graduates", Education and Training, Vol. 50 No. 5, pp. 366-78.

Shepherd, D.A. (2004), "Educating entrepreneurship students about emotion and learning from failure", Academy of Management Learning and Education, Vol. 3 No. 3, pp. 274-87.

Squire, K. and Jenkins, H. (2003), "Harnessing the power of games in education", Insight, Vol. 3 No. 1, pp. 3-31.

Sternberger, C. (1995), “Adult teaching strategies”, Adult Learner, Vol. 6 No. 4, pp. 12-14.

Verzat, C., Byrne, J. and Fayolle, A. (2009), "Tangling with Spaghetti: pedagogical lessons from games", Academy of Management Learning and Education, Vol. 8 No. 3, pp. 356-69.

Warner, A. (2005), "An egg-centric approach to teaching strategic types: adapting a classic exercise”, Journal of Management Education, Vol. 29 No. 4, pp. 583-92.

Yamazaki, Y. and Kayes, D.C. (2004), "An experiential approach to cross cultural learning: a review and integration of competencies for successful expatriate adaptation”, Academy of Management Learning and Education, Vol. 3 No. 4, pp. 362-79.

Zantow, K., Knowlton, D.S. and Sharp, D.C. (2005), "More than fun and games: reconsidering the virtues of strategic management simulations", Academy of Management Learning and Education, Vol. 4 No. 4, pp. 451-8.

\section{Appendix. The pasta game description}

\section{Round 1: arched bridge building}

Objective: to build an arched bridge from one table to another. The arched bridge must be capable of bearing weight. The team with the strongest arched bridge wins.

Logistics: students are assigned to pre-assigned groups. Each group has to build an arched bridge using the materials provided. The game is arranged as a competition between the groups. Groups have 30 minutes in which to build their "arched bridges", which are tested to see what weight they can hold.

Material: (per group) penne pasta, sewing thread, weights, a weight holder (plastic bag which can be placed under the arched bridge and connected to the highest point of the bridge), straws and sticky tape.

Directions: build an arched bridge from one table to another. The arched bridge must rest on each table top. Students are permitted to place a hand on each end of the arched bridge where it touches the table. Each group needs to consider carefully how to support the top of their arched bridge to enable weight testing to occur successfully, otherwise their arched bridge will collapse as soon as the weights are attached.

Measures: the strongest arched bridge is defined by its capability to carry the maximum load. The weight that each team's arched bridge can support is recorded on the whiteboard.

You will dismantle your construction upon completion of the exercise. This exercise will be timed to stop (complete or incomplete at the end of allocated time of 30 minutes).

End of Round 1. 
Objective: to build a tower made of pasta that is at least $120 \mathrm{~cm}$ in height and which is capable of bearing marble weights at the top of the tower. The team with the strongest tower wins.

Logistics: students continue working in their pre-assigned groups. Each group has to build a tower using the materials provided. Similarly, at the end of the allotted time (30 minutes), the towers are tested to see what weight they can hold.

Material: (per group) pasta, sewing threads, weights, basket for the weights which can be placed on top of the tower, two cups, straws and sticky tape.

Directions: build a free-standing tower which is $120 \mathrm{~cm}$ in height. The tower is to be built on the table top.

Measures: the strength of the tower is measured by placing weights in the cup/ basket holder at the top of the tower. Each tower's carrying capacity is recorded on the classroom whiteboard. The strongest tower is the tower which can carry the heaviest load.

End of Round 2.

\section{Corresponding author}

Soma Pillay can be contacted at: soma.pillay@monash.edu 